\section{A literatura da fé material}

\author{
I va n K i ma \\ Traduçăo de RILDO cossoN
}

Desde que o homem tornou-se consciente de sua existência, ele tornou-se, também, consciente do outro lado da existência, sua inexistência. Um homem vem e passa enquanto o mundo, a vida e o tempo continuam. Na história da cultura podemos observar como as pessoas ajustaram-se ao paradoxo irrevogável da vida, e à questão do significado da vida, se houver algum, em referência a este paradoxo.

Ainda que a cultura oriental possa diferir da ocidental no conceito de Deus e de nossa conduta, no princípio, suponho, as questões eram as mesmas: como usar o tempo que é adjudicado ao homem, como fazer frente à sua própria mortalidade, como vencê-la? Face a face com a natureza, onde tudo está constantemente surgindo e desaparecendo, o homem tentou encontrar algo permanente que desafiasse a destruição, algo ou alguém a quem pudesse rogar, de quem pudesse inferir que ele, pelo menos, não perderia a esperança de permanência.

Quanto mais o homem separa-se da natureza, quanto mais difere dos outros seres vivos, mais o homem percebe que Ele, o qual está acima do mundo da vida, concedeu-lhe um amor especial. O homem foi criado e revelado à Sua imagem. Poderia alguém admitir que Ele, concedendo tal graça ao homem, poderia também renegá-lo tanto a ponto de fazê-lo semelhante a outras criaturas, a quem foi dado apenas uma ilhota insignificante no mar da vida? O homem suspeita que tem, no mínimo, um reflexo da grandeza e imortalidade de Deus. Ele tem uma alma. Ela não está sujeita a morrer como o corpo, ela é eterna ou, pelo menos, aspira à elevação, na qual se unirá a Deus, de quem ela veio.

Contudo, mesmo esta esperança não agrada totalmente o homem, pois ele recebeu a mais deleitosa das novas: o Filho de Deus sobre a cruz quebrou o poder da morte. Cristãos professaram e continuam a professar: eu acredito no corpo ressuscitado da morte. O homem pode entrar na eternidade fisicamente e, não apenas, como um espírito. Se os discípulos de Cristo tivessem trazido apenas esta promessa, eles certamente teriam encontrado multidões de seguidores, multidões ansiosas por uma nova fé na vida após a morte.

Contudo, mesmo no consolo das boas novas de vencer à morte, ainda permanece a divisão desanimadora do mundo da morte e do mundo da vida, terra de céu, pessoas de Deus. Não se tem nenhuma palavra de esclarecimento. Uma mente, que está acostumada a questionar, pergunta sobre a lógica desta separação e começa a duvidar Todavia, recebe a réplica: se você não quer perecer, acredite! A fé salvará você, somente através da fé o homem estará liberto do domínio da inexistência.

O homem difere das outras criaturas vivas na sua consciência, sua mente, sua habilidade para questionar, para buscar associações, causas e leis. Porém, então, ele entra num domínio onde ordena a si próprio: não questione, simplesmente acredite, ou você perecerá. Quanto mais a razão descobre os mistérios do mundo material, mais se aprofunda e solidifica-se o dualismo da razão e fé.

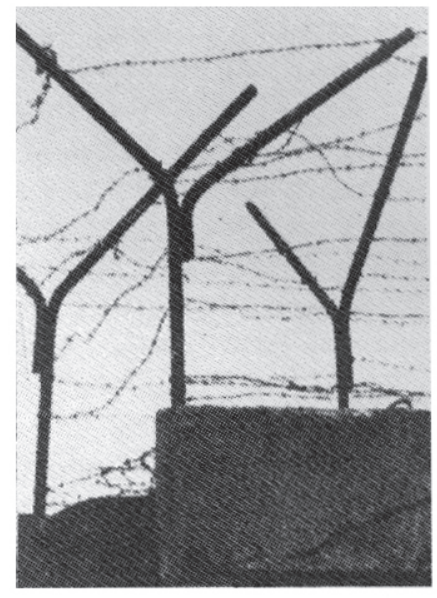

IVAN KLIMA é escritor, ensalsta e dramaturgo tcheco. Foi um dos fundadores do movimento conhecido como Carta 77, junto, entre outros, com Vaclav Havel, atual presidente da República Tchecoslovaca. O presente artigo foi cedido pela revista Aproximaçóes. 
Não me sinto constrangido a elaborar um resumo do que tem acontecido, por tanto tempo, entre a razão e a fé. Porém, penso que posso sustentar que nos últimos dois séculos surgiram pessoas para quem alguns artigos de fé, como expressados pelos dogmas da Igreja, são totalmente inaceitáveis. Estudantes do racionalismo, filhos da idade industrial ou atômica sentem ou, pelo menos, receiam repetir a proposição de que o corpo será ressuscitado no final dos tempos. Alguém que deseja acreditar não pode, freqüentemente, fazê-lo como seus pais, e, em vez do consolo da fé, ele sente a angústia do nada. Há um século e meio, um poeta expressou brilhantemente os sentimentos de um homem face a face com um universo sem Deus:

"Uma estrela do céu foi lançada, Uma estrela agonizante de luz azulada;

Cai por toda a eternidade,

Cai para a infinidade.

Seu pranto parece vir do escuro túmulo do mundo, a voz da perdição, um lamento profundo.

'Quando sua peregrinação será concluída?'

Nunca, em lugar nenhum, terá guarida.’*

No entanto, pode o homem viver constantemente na angústia do nada? Ele tem que encontrar algum sentido em seus atos, algum objetivo para sua vida, mesmo se ele não procura onde seus predecessores tinham procurado por séculos. Chegou o tempo de novas crenças. As multidões ouvem e seguem-nas. A ânsia de acreditar no sentimento e na salvação continua, somente a crença e o sujeito do culto foram mudados. A fé é trazida do céu para a terra, da vida após a morte para a existência terrena. Deus não é reverenciado, mas sim o homem, mais e mais freqüentemente o mero símbolo do homem, incorporado por um grande líder.

O escritor, também, nos tempos modernos é, freqüentemente, incapaz ou relutante em aceitar a fé que, para seus predecessores, teria significado salvação. Porém ele pode repetir incontáveis vezes: Exegi momumentum aere perenius não anula o paradoxo fundamental de sua existência ou inexistência. E que esperança este paradoxo traz aos homens?

Entretanto, muitos escritores sentem serem, eles mesmos, sucessores dos profetas. Eles desejam possuir a mesma necessidade e pathos, empenham-se, como os profetas, em admoestar e elevar para as coisas mais altas. Contudo, eles carecem daquele que enviou os profetas, ou, pelo menos, Ele não está evidente.

No século passado, surgiu uma poderosa corrente de tal admonitória literatura profética. Autores tais como Dickens, Zola e Hugo viram o mundo de maneira semelhante: a sociedade humana é injusta, o mundo é na maior parte das vezes sombrio. Os autores estavam, principalmente, interessados no espaço onde dramas sociais, ou melhor tragédias, desenrolavam-se; onde por um lado predominava a miséria e sofrimento como resultado da desigualdade social, e por outro governava o cínico e imoral poder do dinheiro. Essa indignação profética contra o estado miserável da vida dos homens continua, hoje, a ter seus adeptos, mas no princípio eles careciam de algo - o penhasco do qual o profeta falava. Em nome de quem e o que ele admoestaria? o que ofereceria? Ele sabia que a pobreza é má, porém afirmava que a riqueza corrompe as pessoas. E que a vida de um homem que nada tem é jogada aqui e acolá, de um lado para o outro.

As pessoas para quem os profetas materialistas pregavam ainda guardavam a mensagem de libertação. Foi possível ouvi-la? Tudo estava pronto para a recepção de algum ensinamento que traria a salvação. A era das grandes ideologias tinha começado.

Todas as ideologias, que tão fatidicamente influenciaram a história da primeira metade do século XX, nasceram muito tempo atrás no século XIX. Todavia, a necessidade geral, a sede crescente por uma doutrina remidora deu-lhes a aparência universal e elevou-as acima das vidas das pessoas. Porém, de todas as doutrinas, a que mais influenciou o destino humano foi a teoria do socialismo científico de Marx, de uma ordem social mais justa que, depois da revolução vitoriosa, seria realizada pelas classes trabalhadoras.

$\mathrm{Na}$ nova sociedade, que emergiria depois da revolução, o homem não exploraria o homem. A tecnologia, que serviria ao bem-estar humano, eliminaria o labor extenuante. A riqueza da sociedade seria distribuída de acordo com os méritos. $\mathrm{O}$ rendimento ime-

"Maio", K. H. Macha. Traduçăo de R. Cosson. recido e a pobreza dos trabalhadores desapareceriam. Gradualmente, conforme a rique-

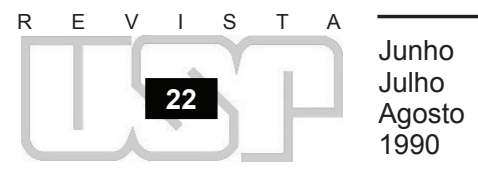


za social fosse desenvolvida, todos seriam satisfeitos de acordo com as suas necessidades. Mais tarde o Estado, dinheiro e propriedade privada desapareceriam, assim como a alienação do homem por causa do trabalho, do homem por causa do proprio homem. $\mathrm{O}$ paraíso desceria das alturas do céu para a terra.

Finalmente, todos aqueles que ansiavam para ser profetas encontraram uma palavra com a qual, como seus predecessores, poderiam arrebatar as multidões: "Socialismo!".

Os escritores que abraçaram a nova doutrina trouxeram para a literatura novas áreas temáticas e novos cenários, e também um herói não-tradicional - um autoconfiante e determinado homem ou mulher (geralmente trabalhadores) de ambientes sociais definidos. (Um protótipo de tal literatura são as obras de Máximo Górki, especiamente a Mãe.) Os escritores socialistas também escreveram sobre as difíceis condições em que numerosas camadas da população viviam, e em nome delas proclamaram a destruição do sistema social existente e a vinda de uma nova ordem social. Foi um alívio para os escritores socialistas terem o seu próprio material, ou o que pensavam ser deles, do qual poderiam criar um reino celestial, um mito de redenção.

Surpreendentemente, o novo mito conservava muitos aspectos da crença que era denunciada nas idéias dos escritores e da sociedade. Ele tinha seus eleitos e sua terra prometida, para a qual o povo seria levado por seus líderes. Também tinham seus ídolos, seus bezerros de ouro, suas tentações que deveriam ser expostas e destruídas. Contudo, precisamente porque este mito era profano, porque a literatura socialista substituía, como Camus escreveu, "objetivos ideais por objetivos reais, vendo o significado da vida humana no modo do homem executar estes objetivos", ele (o mito) trazia em si um perigo. A crença nele era mesmo pior do que a crença naquele que desejava substituir.

O espaço, no qual o homem vivia, sempre fora separado do espaço ideal, quer fosse chamado paraíso ou reino celestial. Essa distância não transformava o mundo em que os homens viviam. Porém, agora, a visão socialista assumia que o mundo ideal surgiria na terra sobre as "ruínas" da velha sociedade. $\mathrm{Na}$ noção revolucionária de uma sociedade ideal (tão distinta da sociedade anterior que se desenvolvia espontaneamente, posto que seria o resultado da atividade racional e deliberada dos "arquitetos" socialistas) apresentava-se dissimulada a idéia de uma "subversão", negação ou, no mínimo, o questionamento dos valores, instituições e experiências que a humanidade tinha acumulado através dos séculos.

A velha noção de eleitos, renovada pela Surpreendentemente, o novo mito do socialismo conservava muitos aspectos da crença que era denunciada nas idéias dos escritores e da sociedade. Ele tinha seus eleitos e sua ferra prometida, para a qual o povo seria levado por seus líderes. Também tinha seus bezerros de ouro, suas tentações... ilusão populista do homem simples, que é o portador da verdade e a origem da sabedoria e da ética incorruptível, estava também embutida ro mito da missão histórica das classes trabalhadoras.

$\mathrm{Na}$ literatura, toda abstração desse tipo, onde verdade e bondade são pré-conhecidas, a abstração que deseja derivar a essência e a imagem do homem de suas origens raciais, nacionais ou de classe social, tem um efeito fatal. $\mathrm{O}$ futuro próximo mostraria como isto funcionaria na vida real.

Pois finalmente - a insensata guerra mundial ajudou - a revolução do proletariado triunfou em um sexto do mundo, o primeiro Estado socialista nasceu. $\mathrm{O}$ sonho de incontáveis profetas socialistas tornou-se realidade. A palavra fez-se vida. A esperança redentora uma vez mais invadia os povos.

As gêmeas - razão e fé - estavam outra vez no mundo. Mas elas diferiam fundamentalmente dos gêmeos tradicionais. $O$ objeto da deificação era o resultado daquela mesma razão que renegou a crença, crença em Alguém que está acima do mundo. A razão desrespeitou a sua própria criação, a sua mais racional realização, e ofereceu-a para a humanidade como uma nova esperança. A distância entre o finito e o infinito, entre o humano e o divino, entre inexistência eterna e imortalidade, entre corpo e alma desapa- 
receu. A esperança perdeu sua dimensão metafísica. A esperança permanecia na organização melhor do mundo. Contudo, pode-se organizar melhor a vida do homem onde a dimensão metafísica está ausente?

A partir do momento em que a palavra tornou-se realidade, a fé socialista, e com ela a literatura socialista, adquiriu uma nova dimensão. Tudo que vivia só na imaginação, ou nos sonhos dos profetas e da sociedade, começou a ser concretizado e isto propiciou resultados.

Numa distância de muitos anos a grande parte do que a revolução trouxe ou perpetrou surge, diferentemente, do que os seus contemporâneos percebiam. É inegável que toda revolução traz a seus seguidores um sentimento embriagante de satisfação, através dela eles não são joguetes da história, mas sim seus criadores ou mesmo seus reformadores. Revoluções, verdadeiramente grandes revoluções, são feitas em nome de nobres e puras idéias, de ideais que prometem livrar as pessoas da miséria em que elas se encontram. O vigoroso sentimento dos revolucionários pode ser comparado aos sentimentos dos apóstolos que espalharam a mensagem da salvação. Como Malraux disse: "A revolução tem, na vida de um revolucionário, o mesmo papel que a vida eterna teve um dia. Que é trazer salvação para aquele que acredita nela".

Ao escritor está, sobretudo, prometida a esperança de que a revolução socialista destruirá todas as cadeias das convenções e leis da sociedade pré-revolucionária, e assim ele entrará no reino da liberdade ilimitada, o qual é muito atraente para todo artista. Ele também acredita que alcançará uma audiência maior e mais atenção numa sociedade onde, em teoria, cultura e, por conseqüência,

Ele (Górki) transformou um campo de concentração em uma instituição bem dirigida, onde são usados "somente métodos de trabalho educacional sob condições da mais ampla liberdade", onde nada se assemelha a uma prisão, "pessoas se educam e aprendem como viver adequadamente..." literatura adquirirão uma esfera de ação sem precedentes, assim que elas cessarem de ser propriedade de uns poucos e tornaram-se propriedade de todas as pessoas - a necessidade comum. Posto que sob o socialismo, de acordo com o sonho delirante de Trotski, "o homem comum adquirirá as dimensões de Aristóteles, Goethe e Marx".

Podemos ficar admirados que os espíritos de tantos escritores estivessem satisfeitos com a sensação de que o destino tem concedido-lhes a oportunidade de participarem nos eventos mais revolucionários da história moderna? Essa sensação tinha uma voz nas primeiras obras "revolucionárias" da literatura socialista, e não seria correto diminuí-las. Maiakóvski e Babel, assim como John Reed ou Mikhail Sholokhov, o autor de $O$ Don Silencioso, certamente deram testemunhe dos seus sentimentos e os sentimentos e experiências daqueles que fizeram a revolução.

Porém, logo estava a chegar o tempo em que aqueles, que lideraram a revolução e tinham feito promessas para a multidão, teriam que prestar contas de suas ações e encontrar muito pouco de que se orgulhar. Eles poderiam oferecer somente paciência e fé - e excomungar aqueles que se recusavam a submeter-se.

A tentação despertada pela Grande Esperança de Salvação ainda continua. A revolução ainda atinge seus objetivos no cerceamento. Assim as grandes idéias necessitam de mais tempo. A maioria dos escritores que encontraram na revolução socialista a realização de seus ideais e idéias, que eram também do país inteiro, não desertaram dos postos de profetas leais. Entre eles estão artistas reconhecidos como Barbusse, Brecht, Rolland, Laxness ou Nexö. Eles nada vêem - eles acreditam. E eles não desejam que alguém mais veja, querem que todos compartilhem a fé deles. "Na terra onde o amanhã já significa ontem" - é como um autor tcheco intitulou seu livro de reportagens laudatórias sobre a terra dos soviéticos. Escritores alegremente espalham slogans sobre a nova justiça, exultam a respeito das fábricas de tratores recentemente concluídas, a respeito dos laços de camaradagem. Eles sabem que se encontram numa terra onde os sonhos estão tornando-se realidade, mas nada sabem sobre centenas de milhares de pessoas 
inocentes que são arrastadas para os campos da Sibéria. O projetado autor russo, Máximo Gorki, foi ainda mais longe. As autoridades pediram-lhe para inspecionar um campo de concentração nas ilhas Solovetski. Ele voltou e escreveu um relatório entusiasmado sobre sua visita. Ele transformou um campo de concentração em uma instituição bem dirigida, onde são usados "somente métodos de trabalho educacional sob condições da mais ampla liberdade", onde nada se assemelha a uma prisão, "pessoas se educam e aprendem como viver adequadamente, têm seu próprio teatro, criam zibelinas, raposas, vacas e porcos. Pela primeira vez eu vi cavalos e vacas mantidos em tal limpeza que você não poderia sentir o acre odor costumeiro...", isto ele escrevia, como alguém que entendia de economia animal, enquanto, com desdém, a respeito dos prisioneiros políticos - "eles são contra-revolucionários do tipo emocional, monarquistas, aqueles que se autodenominavam a Centena Negra antes da revolução. Há também defensores do terror, espiōes do governo e malfeitores, em geral, ervas daninhas que a mão da história está removendo do campo".

Ele foi também conquistado pela beleza única da ilha e de sua natureza. "O áspero lirismo da ilha, em vez de evocar a piedade infrutífera de seus habitantes, provoca uma urgente e quase atormentadora ânsia de trabalhar mais rápido e mais ardentemente pela criação de uma nova realidade..." Contudo, a nova realidade, como um profeta verdadeiro em sua fé sabe, não precisará absolutamente de cárceres, nem aqueles, maravilhosamente livres, campos de treinamento. "Na União Soviética se reconhece que o crime É criado por uma sociedade de classes, e que será erradicado quando erradicarmos as condições propícias ao nascimento da doença - a antiqüíssima e apodrecida base econômica da sociedade de classes..."

De acordo com a declaração posterior de A. Solzhenitsyn, um prisioneiro de 14 anos (!) informou Górki, durante sua visita, de todos os horrores do campo. "Górki saiu das barracas chorando... assim que seu barco partiu, eles assassinaram o rapaz." Se houve tal encontro, o profeta guarda silêncio sobre ele. Além do mais, ele não poderia destruir a imagem do paraíso que estava anunciando. Instruções eram dadas sobre como escrever a respeito da realidade socialista, demonstrava-se como um escritor socialista deveria olhar para a vida que fora instruído para ver ou, mais precisamente, que era para ver somente a vida que lhe era permitida e vê-la somente de uma única maneira.

Nós devemos corrigir a caracterização de Camus da literatura socialista: a literatura socialista vê o significado da vida em como o homem realiza os objetivos proclamados

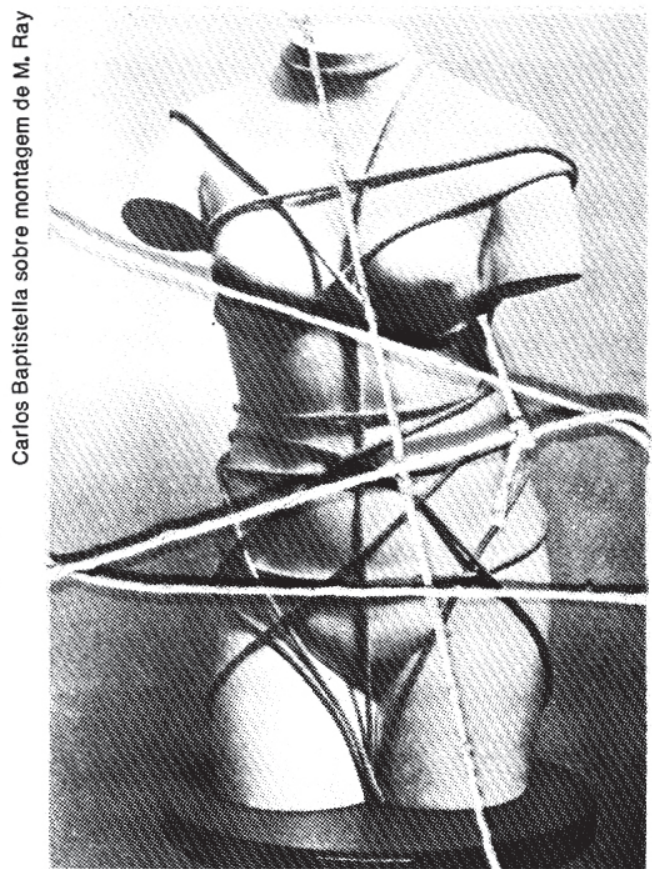
pelo regulamento do poder político na terra da revolução, como ele ajuda, através de suas ações e atitudes, a esse poder estabelecer o seu governo.

Tais contribuições poderiam ser e foram feitas por escritores não somente na terra da revolução, mas também em outro s países. O escritor deve aceitar que o objetivo do poder, na terra da revolução, é construir uma sociedade socialista e mais tarde comunista tão rapidamente quanto possível. A última realizará todos os ideais originais, pois somente então todos conseguirão liberdade e bem-estar. Esse poder opor-se-á à resistência furiosa tanto da reação externa quanto da interna, e, então, algumas medidas extraordinárias serão necessárias. Elas não são importantes para o socialismo, ninguém precisa dar-lhes atenção, elas são causada s pelas condições externas e desaparecerão com estas ao longo do tempo de acordo com as circunstâncias. Ao contrário, é aconselhável enaltecer o poder criativo do povo, seu entusiasmo, seus sucessos inventivos. Quanto mais pessoas estiverem sob seu poder, mais o profeta é solicitado para louvá-las.

"Em nosso país os principais heróis da literatura são os construtores da nova vida, os operários, os trabalhadores das fazendas coletivas, os membros do partido, economistas, engenheiros, membros do Komsomol ou 'pioneiros' (organizações da juventude comu-
Montagem com a montagem de Man Ray de Venus restaurée 
nista). Nossa literatura é inspirada pelo entusiasmo e heroísmo. É fundamentalmente otimista, pois é a literatura de uma classe em ascensão - o proletariado -, uma classe unida, progressista e pioneira... A literatura soviética deve ser capaz de retratar nossos heróis, deve olhar para o nosso amanhã. Ele não será uma utopia, pois nosso amanhã está condicionado por nossa planejada e deliberada ação de hoje" (A. A. Zhdanov).

Ao mesmo tempo, Máximo Górki proclamava como uma lei irrevogável: "A literatura genuína, a verdade genuína está entre heróis do povo, entre esses velhos e eternamente vivos heróis do povo trabalhador como Prometeu, Svyatogor, Ivanushka, Petrushka, e finalmente Lenin".

Essa convocação surgiu num tempo em que os olhos dos profetas, em lugar de ver os portōes do paraíso, viam mais freqüentemente as grades da prisão, quando era difícil para a voz deles não expressar os gemidos do inocente. Assim acontecia. $\mathrm{O}$ desespero $\mathrm{e}$ a tortura de réus confessando o mais inacreditável dos crimes, a fome campeando nas terras recentemente consideradas o celeiro da Europa, pessoas famosas e desconhecidas desaparecendo de suas casas, crentes e ateus, revolucionários e seus oponentes, muitos deles nunca mais vistos outra vez por ninguém. Os mortos amontoavam-se. Livros sobre o assunto aparecem no estrangeiro, há muitas testemunhas prontas a testemunhar; porém, estes, que até recentemente pareciam sensíveis a todo ato de injustiça e clamavam por ajuda a todo sofredor, subitamente nada sabiam sobre aquilo.

Obviamente, como a discrepância entre a realidade e o ideal progredia, ela se automanifestava nos heréticos, nos críticos, e mesmo naqueles que estavam perdendo sua fé,

"Miseráveis e mesquinhos

parasitas. Para o inferno

com eles! Tem sido

provado que o mundo é um

milhão de vezes melhor sem

eles. Teóricos livrescos, revolucionários românticos,

presunçosos e odiosos

desconhecidos, para 0

inferno com eles! Poetas

e artistas decadentes.

Para o inferno com eles!" aqueles que antes se conformavam. A fe tinha que ser sustentada contra eles firme e desapiedadamente, como convinha à defesa da única verdade cientificamente fundada sobre a sociedade.

Em 1936, depois de seu retorno da terra da revolução, um dos primeiros profetas, Andre Gide, publicou um livro com suas reportagens intitulado Retour de I'URSS, onde confessava seu desapontamento e reservas. O livro provocou abomináveis reações entre os ortodoxos. Também, na Tchecoslováquia, S. K. Neumann, um poeta não de todo insignificante, escreveu um livro inteiro intitulado Anti-Gide. Ele cobriu o escritor francês de insultos e zombaria, porem, principalmente, criou uma especie de catecismo em que sumarizava a fé socialista contemporânea. É interessante comparar essa profissão de fé com suas visões utópicas anteriores. Há uma profunda diferença visível na própria linguagem: o pathos foi substituído por convulsibilidade, a visão do futuro cede lugar a mentiras sobre o pre-

sente, insultos e ataques torpes a oponentes e dissidentes, a camponeses, democratas, trotskistas, revisionistas, à intelligentsia, intelectuais, aos pequenos-burgueses, liberais, decadentes e parasitas afugentados todos pelas encorajadoras informações de que somente uma confiança inabalável permanece: que a "União Soviética é a única verdade no mundo de hoje"'.

A revolução uma vez tinha atraído grandes mentes por prometer libertar a humanidade. E agora, subitamente, um suposto defensor dessa herança proclama um conceito de liberdade socialista que está muito mais próxima dos quartéis e dos cárceres do que as versões anteriores.

"O socialismo não pode permitir que qualquer pessoa declare tudo quanto vem à mente, que o partido está envolvido nisto ou naquilo. $\mathrm{O}$ socialismo é um plano e uma ordem que deve ser abraçado por todos. O socialismo não é uma competição livre... não pode suportar individualismo na produção ou nos ramos da superestrutura. $\mathrm{O}$ socialismo aprova somente a pessoa que compr eende o significado e a necessidade do fato de que o plano e a ordem devem ser sustentados por todos, e quem, voluntariamente, sustentaos. $\mathrm{O}$ socialismo rejeita o desejo individual, requer um indivíduo disciplinado e uma

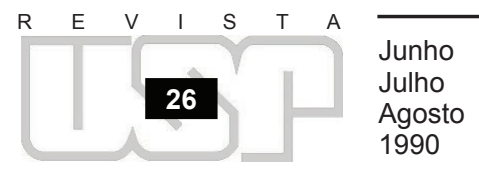


disciplinada individualidade. O socialismo não ê liberdade burguesa, socialismo não é liberalismo, socialismo é disciplina."

Com exatamente tanta ou mesmo mais obstinada paixão, o autor, que começou como um decadente e anarquista, que em seu periódico foi o primeiro, em tcheco, a publicar o anteriormente desconhecido autor Franz Kafka, agora amaldiçoa intelectuais decadentes e defende o direito do poder socialista de lidar implacavelmente com os "intelectuais", a quem o poder ou seus profetas designaram como inimigos do povo. Quem, pergunta o autor, não se sente livre na União Soviética? E ele, que nunca passou um minuto lá, replica como um dos ungidos:

"Miseráveis e mesquinhos parasitas. Para o inferno com eles! Tem sido provado que o mundo é um milhão de vezes melhor sem eles. Teóricos livrescos, revolucionários românticos, presunçosos e odiosos desconhecidos. Para o inferno com eles! Poetas e artistas decadentes. Para o inferno com eles! Dez vidas de tais indivíduos não são equivalentes à vida de um trabalhador decente que poderia perecer através da sua sabotagem".

Era possível ver mais claramente os abismos para os quais, pela cegueira de sua fé materialista, os profetas foram conduzidos? Como a literatura, que ainda afirma que serve aos nobres interesses da humanidade, justiça e melhor ordem social, transforma-se para defender a escravização e o assassinato em massa?

Os profetas sempre tenderam a ser unilaterais e parciais em seus argumentos. Enquanto os profetas que se sentem arautos da missão divina desenvolvem suas opiniões e conjecturas acerca do próprio Deus, os profetas da fé profana encontram-se face a face com a realidade da experiência inteiramente terrena. E quanto mais esta experiência divergia das concepções de seus ideais e das promessas recentes, mais eles tinham que encobrir, distorcer e camuflá-la. Eles que uma vez passional, impulsiva e cegamente retrataram a vida que era contrária à esperança (embora fosse de algum modo remota ou ilusória), agora descreviam ilusões e apresentavam-nas como uma vida cheia de esperanças.

Dada, desta maneira, uma diretriz para sua própria obra e missão, uma certa dificuldade artística manifestou-se. $\mathrm{O}$ artista tornou-se um mero administrador, um popularizador de diretrizes e decretos, da sua essência ou justeza; ele não estava ali para julgar. Mesmo depois da Segunda Guerra, obras ortodoxas foram publicadas com base nestas premissas, mas elas não eram estimuladas por causa de seus pontos de vista originais, porém tão somente por virtude de seu conteúdo utilitário, dogmático e influenciador. Um cartaz tem muito pouco em comum com a vida que representa, ou com a arte, à qual está ligado pelo exercício da vontade, e tem dificuldade de expressar qualquer coisa, quanto mais ser inspirador ou convincente.

Mesmo nos países onde exatamente tal criatividade doutrinária é forçada ou, pelo menos, encorajada, tais obras estão gradualmente desaparecendo. Os artistas estão reclamando seus direitos básicos: escrever sobre a vida como eles a vêem, criar de acordo com seus próprios pensamentos e sentimentos, mesmo se eles são perseguidos, punidos e encarcerados por isto. Realmente, nestes países ninguém poderia encontrar, hoje, profetas genuínos da fé terrena. Os antigos morreram e não deixaram nenhum herdeiro.

A literatura socialista, como a mais típica manifestação de uma literatura inspirada por uma doutrina (primeiro ela aparece para dar significado à vida, mas em breve instala-se entre o escritor e a vida), agora pertence ao passado. Todavia, como todo movimento espiritual (ou pseudo-espiritual), ela deixa remanescente na mente do público cada um de seus traços ou uma marca de vazio.

A incessantemente repetida declaração de que a história está encaminhando-se para uma meta profana e específica, isto é, para uma ordem social mais alta, para um bemestar maior, para uma organização melhor da vida humana que o socialismo trará, que agora as pessoas têm o direito ou mesmo o dever de aproveitar certos recursos a fim de atingir aquela meta, não deixou de influenciar a opiniâo pública. Eu diria que uma vaga ou apenas levemente abalada conviç̧ão de que a história está dirigindo-se para alguma meta material maior ainda continua. Embora, talvez, erroneamente definida, perversamente percebida, incorretamente denominada, nós estamos, todavia, encarando-a. Não reconhecê-la, não tentar, significa negar o progresso (e ele existe, não o prova o rápido desenvolvimento da ciência e da tecnologia?). Enquanto esta conviç̧ão existir, o perigo de erupções de novas visões utópicas existirá, de novas ideologias que, presunçosamente, prometerão levar a humanidade para alguma meta maior, sem considerações de custos. 
Muitos dos dogmas, predições, leis e declarações proféticas não resistiram por muito tempo ao encontro com a realidade. A mais importante resistência foi feita pela "linguagem" que a fé criou e trouxe para a consciência geral nas obras de seus profetas. Esta "não somente linguagem morta, mas a linguagem da morte" (Grusha) criou seu próprio dicionário com palavras tabus ou combinaçôes mágicas, cujo único sentido era regular e simplificar a realidade, para que ela pudesse ser expressada no espírito da fé profana.

Qualquer mudança em nosso século está compreendida na percepção geral dos conceitos de individualismo e coletivismo. Todavia, muitos insultos têm sido suportados por termos tais como burgueses, pequenos-burgueses, conservadores ou direitistas. Uma igual, ou aproximadamente igual, medida de reverência religiosa recai sobre palavras tais como prógresso, desenvolvimento, esquerdista ou povo. (Quem ousaria ir contra os interesses do povo ou mesmo afirmaria o fato óbvio de que em nome daquele que $\hat{\varepsilon}$, possivelmente, o mais nebuloso de todos os conceitos, a maioria dos crimes de nosso século foram cometidos?) Nadezhda Mandelshtam recorda o mágico efeito deles:

$O$ papel decisivo na sujeição da intelligentsia não foi exercido pelo terror e a força (Deus sabe, houve bastante de ambos), mas pela própria palavra revolução, que ninguém desejava pronunciar. Era uma palavra que controlava nações. Seu poder era tal que se admira porque nossos líderes ainda usam cárceres e execuções"

A palavra substituiu a evidência. Freqüentemente, uma palavra era suficiente para insinuar-se à sociedade como algo comprovando o que' estava só no desejo ou intenção dos profetas. Um filósofo tcheco denomina este tipo de discurso como "a linguagem da experiência anulada" (Belohradsky) e adverte que todos aqueles que submetessem este discurso ao controle empírico seriam acusados de subjetivismo ou outros ("reacionários", é రbvio) vícios. Se alguém está a devolver ao discurso a sua semântica plena, as palavras devem ter seu encanto quebrado, devem ser libertas do serviço da fé profana e de seus ídolos, ser purificadas do lastro emocional que obscurece seus verdadeiros significados, do mesmo modo que o pensamento daqueles que as usam e ouvem.

Uma pessoa que contempla a história da literatura socialista e o destino de seus criadores não pode, freqüentemente, furtar-se ao sentimento de que está assistindo uma tragédia. Muitos dos autores escreveram o que eles escreveram, e acreditaram no que eles acreditaram, conduzidos por um desejo imenso de ver uma sociedade melhor e mais justa. A sua crença cegou-os e trouxe conseqüências trágicas para suas obras, para as idéias que eles desejavam defender, e freqüentemente para eles mesmos. Alguns deles, quando examinaram seus equívocos, tentaram compensá-los em suas obras, outros mesmos terminaram suas vidas prematuramente.

Contudo, as investigações que nós fixamos sobre a autenticidade da atitude do escritor, sobre a honestidade com que ele trabalha a sua obra, são tais que, menos do que a trágica natureza de seu destino, olhamos apenas para a sua necessidade moral. Sua sorte, sua experiência, como a experiência de defender-se de outras grandes ideologias, é a evidência do fato de que a fé profana despoja um artista de sua individualidade, e, por conseqüência, de sua personalidade. Cega e aliena-o da vida real. Os profetas profanos não percebem que Deus não pode ser substituído por um ídolo material, do mesmo modo como a imortalidade não pode ser alcançada através de uma ordem social melhor. Suas visões de mundo, ainda que suas intenções sejam boas, têm desmoronado para o nada, e elas têm arrastado seus criadores atrás de si. Da profundeza desse nada, eles são incapazes de ver os verdadeiros contornos do mundo e suas atividades. Eles não poderiam por mais tempo atingir as pessoas a quem desejavam falar.

Um escritor que aceita uma visão - ainda que governamental - "estranha" do mun= do, que admite a si mesmo perder sua própria voz, abandona o pré-requisito de toda criação artística - a autenticidade, de que ele e sua consciência são as únicas garantias. $O$ significado genuíno e fundamental da criação é que o criador procura enriquecer a totalidade do conhecimento e da compreensão social, da propria visão do mundo e descobertas da experiência social. É dif́́cil imaginar uma idéia tão sublime que pudesse justificar essa mais alta traição que um artista pudesse permitir a si mesmo, a suas obras e a sua sociedade. 